\title{
Socio-economic differences in exposure to television food advertisements in the UK: a cross-sectional study of advertisements broadcast in one television region
}

\author{
Jean Adams ${ }^{1, *}$, Rachel Tyrrell ${ }^{1,2}$, Ashley J Adamson ${ }^{1,2}$ and Martin White ${ }^{1}$ \\ 'Institute of Health \& Society, Newcastle University, Baddiley-Clarke Building, Richardson Road, Newcastle upon \\ Tyne NE2 4AX, UK: ${ }^{2}$ Human Nutrition Research Centre, Newcastle University, Newcastle upon Tyne, UK
}

Submitted 1 December 2010: Accepted 6 June 2011: First published online 2 August 2011

\begin{abstract}
Objective: To document socio-economic differences in exposure to food advertising, including advertisements for foods high in fat, salt and sugar (HFSS) as defined by the UK Food Standards Agency's Nutrient Profiling Model.

Design: A cross-sectional survey. Information (including product advertised and viewing figures) on all advertisements broadcast in one UK region over one week (6-12 July 2009) was obtained. Food advertisements were identified and linked to nutritional information on the content of advertised foods.

Setting: UK Tyne-Tees television region.

Subjects: Data were sourced from a UK-wide television viewing panel.

Results: Eleven per cent of advertising seen was for food and $63 \%$ of food advertising seen was for HFSS foods. The proportion of all advertising seen that was for food was smaller among viewers in the least $v$. most affluent social grade $(\mathrm{OR}=0 \cdot 98,99 \% \mathrm{CI} 0 \cdot 95,1 \cdot 00)$. There was no difference in the proportion of food advertising seen that was for HFSS food between viewers in the most and least affluent social grades. Total exposure to both all food advertising and HFSS food advertising was $2 \cdot 1$ times greater among the least $v$. the most affluent viewers. Conclusions: While the least affluent viewers saw relatively fewer food advertisements, their absolute exposure to all food and HFSS food advertisements was higher than that of the most affluent viewers. Current UK restrictions prohibit advertisements for HFSS foods during programmes with a high proportion of child viewers. Extending these to all programming may reduce socio-economic inequalities in exposure to these advertisements and in diet and obesity.
\end{abstract}

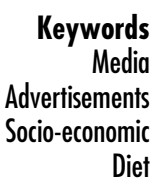

Concern about food advertising has increased in recent years $^{(1-4)}$. Numerous content analyses have documented that the foods promoted on television, in magazines and in outdoor public spaces are strongly biased towards foods that are not considered to make a major contribution to a healthful diet, particularly those that tend to be high in fat, salt and sugar (HFSS) ${ }^{(5-15)}$. Two large reviews have now concluded that food promotion influences children's food preferences, purchasing requests and consumption $^{(16,17)}$. Less information on the effect of food advertising on the preferences and consumption of adults is available. However, recent work has found that the eating behaviour of adults is also affected by exposure to food advertisements ${ }^{(18)}$, suggesting that advertising for less healthy foods is a threat to the health of the whole population, and not just that of children.

Food advertising is, therefore, thought to be part of the causal web responsible for the increasing prevalence of overweight and obesity in children, and adults, in high-income countries ${ }^{(19)}$. In response to these findings, regulation of television food advertising has now been introduced in a number of countries ${ }^{(20)}$. In the UK, regulations on the scheduling and content of television food advertising to children were phased in between April 2007 and January 2009 ${ }^{(21)}$. The scheduling restrictions prohibit advertisements for HFSS foods (those defined as 'less healthy' by the Food Standards Agency's Nutrient Profiling Model $^{(22)}$ ) on children's channels and during or around programmes on other channels with high proportions of viewers aged 4-15 years.

Alongside the increasing prevalence of overweight and obesity in high-income countries is a consistent finding of socio-economic differences in the prevalence of these conditions. Individuals with less education, lower incomes and living in more deprived neighbourhoods tend to have higher rates of overweight and obesity ${ }^{(23)}$. These inequalities are likely to be due to differences in exposure to the environmental determinants of overweight and 
obesity (i.e. all non-genetic determinants) - including food advertising. Very little published work has explored socioeconomic differences in exposure to food advertising, but that which has confirms that less affluent individuals tend to have greater exposure to advertising for less healthy foods than more affluent individuals. In the UK, an analysis of weekly women's magazines found that foods advertised in magazines with less affluent readerships tended to have a less healthy nutritional profile - with higher fat, saturated fat, sugar and $\mathrm{Na}$ content ${ }^{(8)}$. Furthermore, an analysis of food advertisements seen by US children found that food advertisements seen by black children were more likely to be high in fat, sugar or $\mathrm{Na}$ (compared with national dietary recommendations) than those seen by white children ${ }^{(24)}$. While race is not an ideal proxy for socio-economic position, black individuals in the US do tend to be less affluent than white individuals ${ }^{(25)}$.

Using data collected after full implementation of the new scheduling and content restrictions on television food advertising to children, we explored socio-economic differences in exposure to television food advertising in the UK, as well as socio-economic differences in the type and nutritional content of advertised foods.

\section{Methods}

\section{Broadcast data}

In the UK, a small number of channels have regional variants, while most are broadcast nationally. Information on all advertisements broadcast on all channels in one broadcast region, the Tyne Tees region, of the UK during one week, six months after the introduction of the final phase of the new UK scheduling restrictions (6-12 July 2009), was obtained from an audience research bureau (Attentional, Taunton, UK). These data included information on what was advertised, as well as an indicator of the number of viewers aged 4 years and older (television ratings; TVR) of each advertisement, overall and in four social grades. The TVR is the proportion of individuals who live in a household with equipment to receive each advertisement that watched the advertisement.

TVR data were calculated by Attentional from a UK-wide panel of households selected via a multistage, stratified design to ensure representativeness of all households with televisions across the UK in terms of means of television reception, a marker of life stage (pre-family, young family, older family, post-family and retired) and social grade (described below). Panel households, and individual members, receive credits in exchange for participation that can be exchanged for a variety of rewards including high-street shopping vouchers, day trips and household equipment. When a household agrees to join the panel, all television equipment in their home is connected to an electronic monitor that determines what (e.g. television or DVD; television channel) is being shown on each device.
All household members and their guests register their presence when in a room in which a television set is on by pressing the button allocated to them on a handset that accompanies each monitored device. Whenever a panel member leaves a room they de-register their presence using the same handset.

The number of households with equipment to receive each channel varies between channels broadcast on different platforms (e.g. terrestrial, cable, satellite) and across channels with regional variants. TVR for channels with regional variants were based on a panel of viewers in the Tyne Tees region ( $n$ 496), while those for channels broadcast nationally on terrestrial television and other platforms were based on panels of viewers across the UK ( $n 11903$ for terrestrial television; $n 11192$ for other platforms). These panels are nested within each other such that all members of the North East and national 'other platform' panels are also members of the national terrestrial platform panel.

Social grades were assigned using the occupation of the chief income earner in the household in which viewers lived according to the National Readership Survey (NRS) classification system. Social grades AB, C1, C2 and DE represent higher and middle managerial, administrative and professional; supervisors, clerical, junior managerial, administrative and professional; skilled manual; and semi- and unskilled manual occupations, respectively. The NRS classification system also assigns retired people and those reliant on state benefits to social grade DE (http://www.nrs.co.uk/lifestyle.htm).

\section{Nutritional data}

All advertisements for food and drink (collectively referred to as 'food') were identified. We excluded advertisements for alcoholic beverages, food supplements and supermarkets, but included those for fast-food chains.

In order to explore the nutritional content and HFSS status of advertised foods, information on the fruit and vegetable and nutritional content of advertised foods was collected in August-September 2009. Our preference was to use nutritional information from packaging and manufacturers' websites and customer care lines. When this was not available, we relied on supermarket websites and customer care lines. When no other sources of nutritional information were available, we used nearest product matches in standard food table data ${ }^{(26-34)}$ (in 1084 of 91518 ( $1 \cdot 2 \%)$ of food advertisements). We did not mix nutritional information data sources within individual foods, leading to some missing data when, for instance, information on some, but not all, of the nutrients of interest were displayed on packaging. Nutritional data were used to calculate the energy density $(\mathrm{kJ} / 100 \mathrm{~g})$; percentage of energy derived from carbohydrate, sugars, fat, saturated fat and protein; fibre and $\mathrm{Na}$ density ( $\mathrm{g} / \mathrm{MJ}$ ); and, alongside information on fruit and vegetable content, the HFSS status of each food advertised. 
As the analysis was conducted at the level of the individual advertisement, it was necessary to have a single 'set' of nutritional information for each food advertisement. However, in some cases, the information in the broadcast data set was not detailed enough to identify a single product (e.g. Branston Relish listed but six varieties of this product exist). This situation occurred in 38495 of 91518 (42.1\%) of food advertisements. Following comparison with a sample of advertisements from one channel (ITV1 - the most viewed commercial channel in the UK) we had recorded on DVD, we established this occurred when a range of products was shown (e.g. all varieties of Branston Relish), a single product was shown (e.g. Branston Hot Chilli and Jalapeno Relish) but this detail was not included in the broadcast data set, or no food products were shown (e.g. only a food brand logo shown or an advertisement was for a fast-food chain rather than a specific product). Using the broadcast data set alone, it was impossible to distinguish between these scenarios. In all these cases, we attempted to impute nutritional data on the top-selling product in the relevant brand range over the four weeks following broadcast of the advertisement (data provided by TNS (London, UK), a market research company). Where TNS did not have market share data (primarily food sold ready to eat by fast-food chains) or a multi-flavour pack was the top seller, the mean nutritional content of all products in the full range or multiflavour pack, weighted according to relative pack (or suggested portion) size, was calculated and used. Thus the nutritional information attached to advertisements that were labelled solely with the name of a fast-food chain in the broadcast data set was a weighted mean of the nutritional content of all products sold by that chain.

In order to explore the types of food advertised, the single products attached to each food advertisement (as described above) were grouped into food categories. We used the five categories in the UK Food Standards Agency's 'Eatwell plate' ${ }^{\text {(35) }}$ plus two additional categories (see Table 2 for full list of categories) as this is a well-known, policyrelevant classification tool. Advertisements for fast-food chains were categorised as 'meals, combination foods, soups \& sauces'.

\section{Statistical analysis}

To derive a measure of 'exposure' to advertising and take into account the varying audience size and length of different advertisements, person-minute-views (PMV) for each advertisement were calculated by multiplying the total number of people watching by the length of each advertisement, in minutes. The total number of people watching any advertisement was calculated by converting TVR data from percentages to proportions (i.e. dividing by 100) and multiplying the result by the number of panel members for the relevant channel. Thus, one PMV equates to one panel member watching one advertisement lasting $1 \mathrm{~min}$, two panel members watching one advertisement lasting $30 \mathrm{~s}$, or one panel member watching three advertisements lasting $20 \mathrm{~s}$, etc.
Total minutes viewed per person per week (MVPW) were also estimated by dividing the total PMV for viewers in each social grade by the number of terrestrial television panel members in that social grade. As viewing panels for different platforms are nested within each other (see above), there is no clear 'denominator' (e.g. total panel size that refers to all platforms combined) that could be used in these calculations and so we used the size of the terrestrial television panel as our 'best guess' for this figure.

For each social grade, we calculated the number and proportion of advertising PMV and MVPW that were for food, and the number and proportion of all advertising and food advertising PMV and MVPW that were for HFSS foods. Proportions among viewers in social grades C1, C2 and $\mathrm{DE}$ were compared with those in social grade $\mathrm{AB}$ using odds ratios (and 99\% confidence intervals). The distribution of food advertising PMV and MVPW across food categories was calculated and distributions among viewers in social grades C1, C2 and DE were compared with that in social grade $\mathrm{AB}$ using the $\chi^{2}$ test. Average nutritional content of food advertisements, weighted according to PMV, was described using medians (and interquartile ranges) as the distributions of all nutritional metrics were noticeably skewed.

In order to minimise the risk of type 1 statistical error, a $P$ value of $<0.01$ was used to indicate statistical significance throughout. All analyses were conducted using the STATA statistical software package version 11.0 (StataCorp., College Station, TX, USA).

\section{Results}

A total of 207 channels broadcast 607867 advertisements during the study period. Of these, $91518(15 \cdot 1 \%)$ were food advertisements and 60600 were for HFSs foods ( $66 \cdot 2 \%$ of food advertisements; $10 \cdot 0 \%$ of all advertisements). A total of 975278 PMV of advertisements, 135753 PMV of food advertisements $(13.9 \%$ of PMV for all advertisements) and 85143 PMV of advertisements for HFSS foods (62.7\% of PMV for food advertisements; $8.7 \%$ of PMV for all advertisements) were made by members of the viewing panel (Table 1). The proportion of all advertising seen that was for food was smaller among viewers in social grade $\mathrm{DE}$ than those in social grade $\mathrm{AB}$ $(\mathrm{OR}=0.98 ; 99 \% \mathrm{CI} 0.95,1 \cdot 00)$, while the proportion of food advertising seen that was for HFSS foods was higher in viewers in social grade $\mathrm{C} 1$ than in those in social grade $\mathrm{AB}(\mathrm{OR}=1 \cdot 05 ; 99 \% \mathrm{CI} 1 \cdot 00,1 \cdot 10)$. There were no clear trends in either metric across social grades and the magnitude of these differences was small. However, total MVPW of advertisements, food advertisements and HFSS food advertisements increased progressively across social grades from social grade $\mathrm{AB}$ to $\mathrm{DE}$. Viewers in social grade DE saw, on average, more than twice as much 


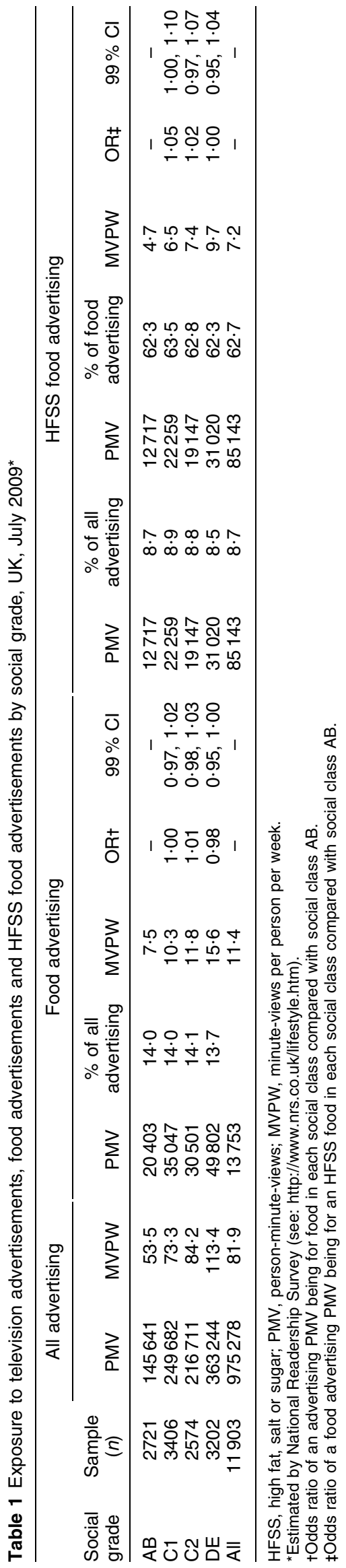

advertising, food advertising and HFSs food advertising than those in social grade $\mathrm{AB}$.

The most frequently represented food categories that food advertisements fell into were 'foods and drinks high in fat and/or sugar' (29.0\% of food advertising PMV) and 'bread, rice, potatoes, pasta' (23.9\% of food advertising PMV; Table 2). The least frequently represented categories were 'fruit \& vegetables' and 'meat, fish, eggs, beans' (both categories accounting for $3 \cdot 4 \%$ of food advertising PMV). The distribution of food advertising PMV across food categories differed significantly among viewers in social grades $\mathrm{C} 1$ and DE compared with viewers in social grade $\mathrm{AB}$, but not for viewers in social grade C2. Again, the magnitude of these differences was small with the most marked differences being a lower proportion of food advertising PMV being devoted to 'milk \& dairy foods' among viewers in social grade C1 compared with those in social grade $\mathrm{AB}(13 \cdot 7 \% v .14 \cdot 7 \%)$; and lower proportions being devoted to 'foods and drinks high in fat and/or sugar' among viewers in social grades $\mathrm{C} 2$ and DE compared with those in social grade $\mathrm{AB}(28 \cdot 8 \%$ and $28 \cdot 7 \%$ v. 29.9\%). There was some indication of a trend for the proportion of food advertising PMV devoted to 'foods and drinks high in fat and/or sugar' to decrease progressively as the social class of viewers became less affluent.

Table 3 shows the median nutritional content of food advertisements seen - weighted by PMV of viewers in each social grade. Also shown are recommended ranges for a diet recommended by the WHO/FAO for avoidance of diet-related diseases ${ }^{(36)}$. Compared with this recommended diet, advertised foods tended to be lower in protein, higher in sugars and lower in fibre. The nutritional content of advertised foods was within recommended ranges in terms of percentage of energy derived from carbohydrate, fat and saturated fat, and Na density. Few differences were seen in the nutritional content of advertised foods seen by viewers in different social grades. However, the most marked differences in median nutritional content of advertised foods seen by viewers in different social classes was a higher percentage of energy derived from fat and saturated fat in all other social grades compared with those in social grade AB.

\section{Discussion}

This is the first comprehensive analysis of variations in television food advertisements seen by viewers in different socio-economic groups in the UK.

\section{Summary of findings}

We estimate that, on average, individuals in the UK view almost $1 \cdot 4 \mathrm{~h}$ of television advertising per week, including more than $11 \mathrm{~min}$ of food advertising and more than $7 \mathrm{~min}$ of advertising for 'less healthy' foods. Advertised foods tend to be higher in sugar and lower in protein and 
Table 2 Food categories of television food advertising seen by social grade, UK, July 2009

\begin{tabular}{|c|c|c|c|c|c|c|c|c|c|c|c|c|c|c|c|}
\hline \multirow[b]{2}{*}{ Food category } & \multicolumn{3}{|c|}{ Social grade $A B$} & \multicolumn{3}{|c|}{ Social grade $\mathrm{C} 1$} & \multicolumn{3}{|c|}{ Social grade C2 } & \multicolumn{3}{|c|}{ Social grade DE } & \multicolumn{3}{|c|}{ All } \\
\hline & PMV & $\begin{array}{l}\% \text { of food } \\
\text { advertising }\end{array}$ & MVPW & PMV & $\begin{array}{l}\% \text { of food } \\
\text { advertising }\end{array}$ & MVPW & PMV & $\begin{array}{l}\% \text { of food } \\
\text { advertising }\end{array}$ & MVPW & PMV & $\begin{array}{l}\% \text { of food } \\
\text { advertising }\end{array}$ & MVPW & PMV & $\begin{array}{l}\% \text { of food } \\
\text { advertising }\end{array}$ & MVPW \\
\hline $\begin{array}{l}\text { Bread, rice, potatoes, } \\
\text { pasta }\end{array}$ & 4816 & $23 \cdot 6$ & $1 \cdot 8$ & 8454 & $24 \cdot 1$ & $2 \cdot 5$ & 7370 & $24 \cdot 2$ & $2 \cdot 9$ & 11839 & $23 \cdot 8$ & $3 \cdot 7$ & 32479 & $23 \cdot 9$ & $2 \cdot 7$ \\
\hline Fruit and vegetables & 659 & $3 \cdot 2$ & $0 \cdot 2$ & 1235 & $3 \cdot 5$ & $0 \cdot 4$ & 1015 & $3 \cdot 3$ & 0.4 & 1684 & $3 \cdot 4$ & 0.5 & 4593 & $3 \cdot 4$ & 0.4 \\
\hline Meat, fish, eggs, beans & 645 & $3 \cdot 2$ & $0 \cdot 2$ & 1149 & $3 \cdot 3$ & $0 \cdot 3$ & 1030 & $3 \cdot 4$ & $0 \cdot 4$ & 1855 & $3 \cdot 7$ & $0 \cdot 6$ & 4679 & $3 \cdot 4$ & $0 \cdot 4$ \\
\hline Milk and dairy foods & 3003 & $14 \cdot 7$ & $1 \cdot 1$ & 4784 & $13 \cdot 7$ & $1 \cdot 4$ & 4378 & $14 \cdot 4$ & $1 \cdot 7$ & 7232 & $14 \cdot 5$ & $2 \cdot 3$ & 19397 & $14 \cdot 3$ & $1 \cdot 6$ \\
\hline $\begin{array}{l}\text { Foods and drinks high in fat } \\
\text { and/or sugar }\end{array}$ & 6098 & $29 \cdot 9$ & $2 \cdot 2$ & 10232 & $29 \cdot 2$ & $3 \cdot 0$ & 8786 & $28 \cdot 8$ & $3 \cdot 4$ & 14312 & $28 \cdot 7$ & $4 \cdot 5$ & 39428 & $29 \cdot 0$ & $3 \cdot 3$ \\
\hline $\begin{array}{l}\text { Meals, combination foods, } \\
\text { soups and sauces }\end{array}$ & 2894 & $14 \cdot 2$ & $1 \cdot 1$ & 4963 & $14 \cdot 2$ & $1 \cdot 5$ & 4367 & $14 \cdot 3$ & $1 \cdot 7$ & 7180 & $14 \cdot 4$ & $2 \cdot 2$ & 19404 & $14 \cdot 3$ & $1 \cdot 6$ \\
\hline $\begin{array}{l}\text { Other foods* } \\
\text { All foods }\end{array}$ & $\begin{array}{r}2288 \\
20403\end{array}$ & $11 \cdot 2$ & $\begin{array}{l}0 \cdot 8 \\
7 \cdot 5\end{array}$ & $\begin{array}{r}4230 \\
35047\end{array}$ & $12 \cdot 1$ & $\begin{array}{r}1 \cdot 2 \\
10 \cdot 3\end{array}$ & $\begin{array}{r}3555 \\
30501\end{array}$ & $11 \cdot 7$ & $\begin{array}{r}1 \cdot 4 \\
11 \cdot 8\end{array}$ & $\begin{array}{r}5700 \\
49802\end{array}$ & $11 \cdot 4$ & $\begin{array}{r}1 \cdot 8 \\
15 \cdot 6\end{array}$ & $\begin{array}{r}15773 \\
135753\end{array}$ & $11 \cdot 6$ & $\begin{array}{r}1 \cdot 3 \\
11 \cdot 4\end{array}$ \\
\hline $\begin{array}{l}\chi^{2}(\mathrm{df}=6) \text { compared with } \\
\mathrm{AB}(P \text { value })\end{array}$ & - & - & & 25864 & $<0.001$ & & 11923 & 0.064 & & 22267 & 0.001 & & - & - & \\
\hline
\end{tabular}

PMV, person-minute-views; MVPW, minute-views per person per week.

*Includes diet soft drinks, sweeteners, tea, coffee, gum.

Table 3 Nutritional content of television advertised foods seen by social grade, UK, July 2009

\begin{tabular}{|c|c|c|c|c|c|c|c|c|c|c|c|c|c|c|c|}
\hline \multirow{3}{*}{$\begin{array}{l}\text { Nutritional metric } \\
(\text { WHO/FAO range, where available) })^{*}\end{array}$} & \multicolumn{15}{|c|}{ Weighted by PMV } \\
\hline & \multicolumn{3}{|c|}{ Social grade $A B$} & \multicolumn{3}{|c|}{ Social grade $\mathrm{C} 1$} & \multicolumn{3}{|c|}{ Social grade C2 } & \multicolumn{3}{|c|}{ Social grade DE } & \multicolumn{3}{|c|}{ All } \\
\hline & Median & 25th & 75th & Median & 25th & 75th & Median & 25th & 75th & Median & 25th & 75th & Median & 25th & 75th \\
\hline Energy density, $\mathrm{kJ} / 100 \mathrm{~g}$ & 960 & 296 & 1641 & 1069 & 453 & 1641 & 1069 & 453 & 1623 & 960 & 453 & $\begin{array}{l}1541 \\
20 \cdot 8\end{array}$ & $\begin{array}{l}960 \\
8.6\end{array}$ & $\begin{array}{l}453 \\
2.5\end{array}$ & $\begin{array}{l}1641 \\
? 0 \cdot 8\end{array}$ \\
\hline$\%$ energy from protein $(10-15 \%)$ & $8 \cdot 6$ & $2 \cdot 5$ & $21 \cdot 3$ & $8 \cdot 6$ & $4 \cdot 9$ & $18 \cdot 6$ & $8 \cdot 6$ & 4.9 & $20 \cdot 8$ & $8 \cdot 6$ & $4 \cdot 9$ & $20 \cdot 8$ & $8 \cdot 6$ & $2 \cdot 5$ & $\begin{array}{l}20 \cdot 8 \\
75 \cdot 9\end{array}$ \\
\hline$\%$ energy from carbohydrate (55-75\%) & $58 \cdot 1$ & $32 \cdot 9$ & $76 \cdot 4$ & $58 \cdot 5$ & $33 \cdot 0$ & $76 \cdot 4$ & $58 \cdot 1$ & $33 \cdot 0$ & $75 \cdot 9$ & $58 \cdot 1$ & $32 \cdot 9$ & $75 \cdot 9$ & $56 \cdot 7$ & $33 \cdot 0$ & $75 \cdot 9$ \\
\hline$\%$ energy from sugars $(<10 \%)$ & $23 \cdot 7$ & $1 \cdot 3$ & $44 \cdot 8$ & $23 \cdot 7$ & $1 \cdot 3$ & $44 \cdot 8$ & $23 \cdot 7$ & $3 \cdot 4$ & $44 \cdot 8$ & $23 \cdot 7$ & $1 \cdot 3$ & $44 \cdot 8$ & $25 \cdot 0$ & $1 \cdot 3$ & $44 \cdot 8$ \\
\hline$\%$ energy from fat $(15-30 \%)$ & $14 \cdot 6$ & $5 \cdot 2$ & $41 \cdot 8$ & $19 \cdot 3$ & $5 \cdot 4$ & $41 \cdot 8$ & $19 \cdot 3$ & $5 \cdot 4$ & $41 \cdot 8$ & $19 \cdot 3$ & $5 \cdot 4$ & $43 \cdot 2$ & $21 \cdot 2$ & $5 \cdot 4$ & $43 \cdot 2$ \\
\hline$\%$ energy from saturated fat $(<10 \%)$ & $4 \cdot 3$ & $1 \cdot 3$ & $18 \cdot 8$ & $5 \cdot 4$ & $1 \cdot 3$ & $18 \cdot 8$ & $5 \cdot 4$ & $1 \cdot 3$ & $18 \cdot 8$ & $5 \cdot 4$ & $1 \cdot 3$ & $18 \cdot 8$ & $5 \cdot 6$ & $1 \cdot 6$ & $18 \cdot 8$ \\
\hline Na density, g/MJ (<0.2 g/MJ) $\dagger$ & 0.2 & $0 \cdot 1$ & 0.4 & 0.2 & 0 & $0 \cdot 4$ & $0 \cdot 2$ & $0 \cdot 1$ & $0 \cdot 4$ & $0 \cdot 2$ & $0 \cdot 1$ & $0 \cdot 4$ & $0 \cdot 2$ & $0 \cdot 1$ & $0 \cdot 4$ \\
\hline Fibre density, g/MJ $(>3.0 \mathrm{~g} / \mathrm{MJ}) \ddagger$ & $1 \cdot 0$ & 0 & $3 \cdot 2$ & $1 \cdot 0$ & 0 & $2 \cdot 7$ & $1 \cdot 2$ & 0 & $3 \cdot 2$ & $1 \cdot 0$ & 0 & $2 \cdot 7$ & $0 \cdot 8$ & 0 & $2 \cdot 7$ \\
\hline
\end{tabular}

\section{PMV, person-minute-views.}

Recommended ranges for prevention of diet-related diseases ${ }^{(36)}$

tBased on a $8.4 \mathrm{MJ} / \mathrm{d}(2000 \mathrm{kcal} / \mathrm{d})$ diet and a recommended daily fibre intake of $>25 \mathrm{~g} / \mathrm{d}$.

fBased on a $8.4 \mathrm{MJ} / \mathrm{d}(2000 \mathrm{kcal} / \mathrm{d})$ diet and a recommended daily $\mathrm{Na}$ intake of $<2 \mathrm{~g} / \mathrm{d}$. 
fibre compared with a diet recommended to avoid dietrelated diseases.

There was some evidence that the proportion of advertising minutes devoted to food, but not the proportion of food advertising minutes devoted to 'less healthy' foods, was lower among the least, compared with the most, affluent viewers. No clear trends in either metric across social groups were seen. While small differences in the type of food advertisements seen were in the direction of 'more healthy' among less affluent viewers, the opposite was trend was seen in terms of nutritional content. In contrast, the overall volume of advertising, food advertising and 'less healthy' food advertising seen by viewers progressively increased as affluence decreased, with those in the least affluent social grade viewing more than twice the volume of all three types of advertising than those in the most affluent social grade.

\section{Strengths and weaknesses}

The work relied entirely on secondary data and this led to a number of methodological strengths, but also limitations. The broadcast data, provided by an audience research company, is likely to be the highest available quality, as these are the data relied on by industry to plan both programming and advertising. However, as viewing figures were provided as TVR, rather than number of individuals actually watching, we had to perform a number of rather complex calculations, and rely on estimates in some cases, to arrive at our results.

Similarly, manufacturer's data on the nutritional composition of advertised foods are likely to be the most product-specific data available. However, we did not view all food advertisements in the sample and this meant we had to rely, in some cases, on informed judgements of the foods shown in advertisements. Viewing all advertisements would have required substantially more resources than available to us.

In addition, we did not take into account other forms of marketing on television - such as product placement. At the time the advertisements included in the present study were broadcast, product placement was not allowed on UK-made television programmes, meaning that the overall contribution of product placement to television food marketing may have been low. While the viewing figures data used took into account playback of recorded television within seven days of broadcast, later playbacks - as well as exposure to food marketing via other screen media, such as online on-demand television - were not included. This is a growing sector that requires further research attention.

Our data were collected six months after full implementation of new regulations restricting television advertising of 'less healthy' foods to children. They, therefore, represent all broadcast television subject to the current regulatory framework in the UK.

The social grading system used is cruder than some systems ${ }^{(37,38)}$. In particular, only four grades are included; all individuals are graded according to the occupation of the chief income earner in their household, rather than in their own right; and retired individuals are grouped with the least affluent grade, irrespective of their previous occupation. Using the NRS social grading system, individuals aged over 65 years account for about $55 \%$ of social grade DE. As we could only access an aggregate, anonymised, viewing figures data set, and this was the classification used in the data set, we were unable to impose an alternative social classification structure. Alternative classification structures may have uncovered some socio-economic trends hidden in the current data.

As previous research and policy interest has focused, in particular, on the effect of food advertising to children, it would have been interesting to explore socio-economic differences in children's exposure to food advertisements. However, viewing figures for specific age-social grade groups are not available (only age-specific or socialgrade-specific) and so we were unable to do this. It is difficult to speculate whether socio-economic differences among children would be similar to those among viewers of all ages reported here.

\section{Interpretation}

Unlike our current findings, previous work on socioeconomic differences in exposure to food advertising has, if anything, found evidence that the relative balance of food advertising seen by less affluent individuals (including black children in the USA) is less healthy than that seen by more affluent individuals ${ }^{(8,24)}$. This highlights that food advertising trends are not necessarily consistent across national boundaries or advertising medium.

Although our results show only small differences in the relative proportions of advertising minutes seen that are for food and food advertising minutes seen that are for 'less healthy' foods across social grades, there were large absolute differences in exposure to both food advertisements and advertisements for 'less healthy' foods. This may be explained by differences in the absolute volume of television watched by individuals in different socioeconomic groups in the $\mathrm{UK}^{(39)}$. These clear absolute differences in exposure to television food advertising may contribute to the socio-economic differences in diet and obesity seen in the $\mathrm{UK}^{(23)}$.

\section{Implications for research and policy makers}

Two potential 'solutions' to the 'problem' of food advertising have been suggested: increased regulation of food advertisements $^{(1-4)}$ and increased training in media literacy skills ${ }^{(1,40)}$. Little research has explored the benefit of media literacy training in terms of response to food advertisements, dietary preferences and consumption, or body weight ${ }^{(41)}$. More work is required in these areas, as well as investigation of any socio-economic differences in the effect of media literacy training.

Worldwide, regulation of food advertisements has focused mostly on those advertisements aimed at, or 
likely to be seen by, children ${ }^{(1)}$. However, there may be a case for extending regulations to all advertisements, or at least all those shown before 21.00 hours, as suggested by recent guidance from the UK National Institute for Health and Clinical Excellence ${ }^{(42)}$. Given the evidence that less affluent viewers are exposed to more food advertising and more advertising for 'less healthy' foods, such regulations are likely to decrease socio-economic inequalities in exposure to food advertising.

\section{Conclusions}

The clear socio-economic inequalities in absolute exposure to advertisements for 'less healthy' food seen here may contribute to known socio-economic differences in diet and obesity. Extending the current UK restrictions on advertising 'less healthy' foods from children's programming to all programming would likely reduce socio-economic inequalities in exposure to these advertisements and may also reduce inequalities in diet and obesity.

\section{Acknowledgements}

Source of funding: This work was funded through the UK National Prevention Research Initiative (http://www.npri. org.uk) with the support of the following organisations: British Heart Foundation; Cancer Research UK; Department of Health; Diabetes UK; Economic and Social Research Council; Food Standards Agency; Medical Research Council; Health \& Social Care Research \& Development Office for Northern Ireland; Chief Scientist Office, Scottish Government Health Directorate; The Stroke Association; Welsh Assembly Government; and World Cancer Research Fund. The award was administered by the Medical Research Council (G0701873). J.A., A.J.A. and M.W. receive salary support from Fuse-the Centre for Translational Research in Public Health, which is funded by the British Heart Foundation, Cancer Research UK, Economic and Social Research Council, Medical Research Council and the National Institute for Health Research, under the auspices of the UK Clinical Research Collaboration. At the time of funding, A.J.A. received salary support from an NIHR Public Health Career Scientist fellowship. Conflicts of interest: No authors have any conflicts of interest to declare. Author contributions: J.A. conceived the idea for this analysis and performed data analysis, R.T. collected nutritional data, all authors made substantial intellectual contributions to the larger from study from which these data are drawn. All authors read and provided critical comments on previous versions of the manuscript.

\section{References}

1. Nestle M (2006) Food marketing and childhood obesity - a matter of policy. N Engl J Med 354, 2527-2529.
2. Halford J (2005) Serving up trouble? Advertising food to children. Psychologist 5, 284-287.

3. Department of Health (2004) Choosing Health: Making Healthy Choices Easier. London: HMSO.

4. Public Health Association of Australia Inc. (2006); Television food advertising during children's viewing times position statement. http://www.phaa.net.au/documents/ TVfoodAdvertPosStatement.pdf (accessed July 2010).

5. Hastings G, Stead M, McDermott L et al. (2003) Review of Research on the Effects of Food Promotion to Children, Final Report for the Food Standards Agency. Glasgow: Centre for Social Marketing.

6. Adams J, Hennessy-Priest J, Ingimarsdóttir S et al. (2009) Changes in food advertisements during 'prime-time' television from 1991 to 2006: a UK-Canada comparison. Br J Nutr 102, 584-593.

7. Adams J, Hennessy-Priest K, Ingimarsdóttir S et al. (2009) Food advertising during children's television in Canada and the UK. Arch Dis Child 94, 658-662.

8. Adams J \& White M (2009) Socio-economic and gender differences in nutritional content of foods advertised in popular UK weekly magazines. Eur J Public Health 19, 144-149.

9. Cowburn G \& Boxer A (2007) Magazines for children and young people and the links to internet food marketing: a review of the extent of food advertising. Public Health Nutr 10, 1024-1031.

10. Folta SC, Goldberg JP, Economos C et al. (2006) Food advertising targeted at school-age children: a content analysis. J Nutr Educ Behav 38, 244-248.

11. Henderson VR \& Kelly B (2005) Food advertising in the age of obesity: content analysis of food advertising on general market and African American television. J Nutr Educ Behav 37, 191-196.

12. Maryam A, Mehdi MR, Masood K et al. (2005) Food advertising on Iranian children's television: a content analysis and an experimental study with junior high school students. Ecol Food Nutr 44, 123-133.

13. Pratt C \& Pratt C (1995) Comparative content analysis of food and nutrition advertisements in Ebony, Essence and Ladies' Home Journal. J Nutr Educ 27, 11-17.

14. Roberts M \& Pettigrew S (2007) A thematic content analysis of children's food advertising. Int J Advertising 26, 357-367.

15. Kelly B, Cretikos M, Rogers K et al. (2008) The commercial food landscape: outdoor food advertising around primary schools in Australia. Aust N Z J Public Health 32, 522-528.

16. Cairns G, Angus K \& Hastings G (2009) The Extent, Nature and Effects of Food Promotion to Children: A Review of the Evidence to December 2008. Prepared for the World Health Organization by Institute for Social Marketing, University of Stirling \& The Open University, UK. Geneva: WHO.

17. McGinnis J, Goolman J \& Kraak V (2006) Food Marketing to Children and Youth: Threat or Opportunity? Washington, DC: The National Academies Press.

18. Harris J, Bargh J \& Brownell K (2009) Priming effects of television food advertising on eating behavior. Health Psychol 28, 404-413.

19. Butland B, Jebb S, Kopelman P et al. (2007) Foresight Tackling Obesities: Future Choices - Project Report. London: Government Office for Science.

20. Kelly B, King L, Bauman A et al. (2007) The effects of different regulation systems on television food advertising to children. Aust N Z J Public Health 31, 340-343.

21. Ofcom (2007) Television Advertising of Food and Drink Products to Children - Final Statement. London: Ofcom.

22. Rayner M, Scarborough P, Boxer A et al. (2005) Nutrient Profiles: Development of Final Model. Final Report for the Food Standards Agency. Oxford: British Heart Foundation Health Promotion Research Group, Department of Public Health, University of Oxford. 
23. Craig R \& Mindell J (2008) The Health Survey for England 2006. vol. 1: Cardiovascular Disease and Risk Factors in Adults. Leeds: The Information Centre.

24. Powell L, Szczypka G, Chaloupka F et al. (2007) Nutritional content of television food advertisements seen by children and adolescents in the United States. Pediatrics 120, 576-583.

25. Krieger N, Williams D \& Moss N (1997) Measuring social class in US public health research: concepts, methodologies and guidelines. Annu Rev Public Health 18, 341-378.

26. Holland B, Unwin I \& Buss D (1988) Cereals and Cereal Products: The Third Supplement to McCance and Widdowson's The Composition of Foods, 4th ed. London: Royal Society of Chemistry \& Ministry of Agriculture, Fisheries and Food.

27. Holland B, Unwin I \& Buss D (1989) Milk Products and Eggs: The Fourth Supplement to McCance and Widdowson's The Composition of Foods, 4th ed. London: Royal Society of Chemistry \& Ministry of Agriculture, Fisheries and Food.

28. Holland B, Unwin I \& Buss D (1991) Vegetables Herbs and Spices: The Fifth Supplement to McCance and Widdowson's The Composition of Foods, 4th ed. London: Royal Society of Chemistry \& Ministry of Agriculture, Fisheries and Food.

29. Holland B, Unwin I \& Buss D (1992) Fruits and Nuts: The First Supplement to McCance and Widdowson's The Composition of Foods, 5th ed. London: Royal Society of Chemistry \& Ministry of Agriculture, Fisheries and Food.

30. Holland B, Welch A \& Buss D (1992) Vegetable Dishes: The Second Supplement to McCance and Widdowson's The Composition of Foods, 5th ed. London: Royal Society of Chemistry \& Ministry of Agriculture, Fisheries and Food.

31. Holland B, Brown J \& Buss D (1993) Fish and Fish Products: The Third Supplement to McCance and Widdowson's The Composition of Foods, 5th ed. London: Royal Society of Chemistry \& Ministry of Agriculture, Fisheries and Food.
32. Chan W, Brown J \& Buss D (1994) Miscellaneous Foods: The Fourth Supplement to McCance and Widdowson's The Composition of Foods, 5th ed. London: Royal Society of Chemistry \& Ministry of Agriculture, Fisheries and Food.

33. Chan W, Brown J, Lee S et al. (1995) Meat, Poultry and Game. Fifth Supplement to McCance and Widdowson's The Composition of Foods, 5th ed. London: Royal Society of Chemistry \& Ministry of Agriculture, Fisheries and Food.

34. Chan W, Brown J, Church S et al. (1996) Meat Products and Dishes. Sixth Supplement to McCance and Widdowson's The Composition of Foods, 5th ed. London: Royal Society of Chemistry \& Ministry of Agriculture, Fisheries and Food.

35. NHS Choices (2011) The eatwell plate. http://www.nhs.uk/ Livewell/Goodfood/Pages/eatwell-plate.aspx (accessed 11 July 2011)

36. World Health Organization (2003) Diet, Nutrition and the Prevention of Chronic Diseases. Report of a Joint WHO/FAO Expert Consultation. WHO Technical Report Series no. 916. Geneva: WHO.

37. Galobardes B, Shaw M, Lawlor D et al. (2006) Indicators of socioeconomic position (part 2). J Epidemiol Community Health 60, 95-101.

38. Galobardes B, Shaw M, Lawlor DA et al. (2006) Indicators of socioeconomic position (part 1). J Epidemiol Community Health 60, 7-12.

39. Lader D, Short S \& Gershuny J (2006) The Time Use Survey 2005, How We Spend Our Time. London: Office for National Statistics.

40. Matthews A (2008) Children and obesity: a pan-European project examining the role of food marketing. Eur J Public Health 18, 7-11.

41. Bergsma LJ \& Carney ME (2008) Effectiveness of healthpromoting media literacy education: a systematic review. Health Educ Res 23, 522-542.

42. National Institute for Health and Clinical Excellence (2010) Prevention of Cardiovascular Disease at Population Level: NICE Public Health Guidance 25. London: NICE. 